\title{
La isla de calor urbana de Palma (Mallorca, Islas Baleares): avance para el estudio del clima urbano en una ciudad litoral mediterránea
}

\author{
The urban heat island in Palma (Majorca, Balearic islands): \\ progress in the study of urban climate in a Mediterranean coastal city
}

\author{
Gabriel Alomar Garau \\ gabriel.alomar@uib.es \\ Departament de Geografia \\ Universitat de les Illes Balears (España)
}

\section{Juan Llop Garau}

jllop@cbba-online.com

Centre Balear de Biologia Aplicada (CBBA) (España)

\section{Resumen}

El presente trabajo presenta un estudio de la isla de calor en la ciudad de Palma (Mallorca). En la investigación se ha adoptado el método de los transectos móviles con el objetivo de identificar el fenómeno y analizar su distribución espacial, para lo cual se han diseñado tres diferentes recorridos y se han realizado un total de catorce mediciones de campo, estivales, otoñales e invernales, en horario diurno y nocturno. El resultado es la identificación de una isla de calor típica en trece de estas mediciones, cuya intensidad varía entre $1.4^{\circ}$ y $5.8^{\circ} \mathrm{C}$, y que parece que es mayor bajo escenarios atmosféricos fríos. Los valores máximos se localizan mayoritariamente en el antiguo casco urbano intramuros, y no tanto en zonas de la ciudad más densamente pobladas y motorizadas, en donde presumiblemente más inercia calórica se genera. El método de los transectos ha permitido localizar también, en un marco general de isla de calor, sectores fríos que 
coinciden con vaguadas y espacios abiertos o arbolados, todo lo cual tiene gran interés para la planificación urbanística con criterios ambientales.

Palabras clave: clima urbano; isla de calor urbana; transectos móviles; Palma; Mallorca.

\begin{abstract}
In this article we present a study of the Urban Heat Island in the city of Palma (Majorca, Balearic Islands). The research has adopted the urban mobile transects method with the objective of identifying the phenomenon and analyzing its spatial distribution, for which three different routes have been designed and a total of fourteen field campaigns have been carried out, in summer, autumn and winter, during daytime and night time. We have identified a typical heat island in thirteen of these campaigns, whose intensity varies between $1.4^{\circ} \mathrm{C}$ and $5.8^{\circ} \mathrm{C}$, and seems to be higher under cold atmospheric scenarios. The maximum values are located mainly in the old urban center, and not so much in zones of the city more densely populated and motorized, where presumably more thermal inertia is generated. Our method has also allowed us to locate, in a general heat island context, cold areas that coincide with thalwegs and open or wooded areas, all of which are of great interest for urban planning with environmental criteria.
\end{abstract}

Key words: urban climate; Urban Heat Island; mobile transects; Palma; Majorca.

\title{
1 Introducción
}

La ciudad de Palma, en la isla de Mallorca (Islas Baleares), reúne todos los elementos de interés a la hora de abordar el estudio del fenómeno de la isla de calor urbana (ICU). Se trata de un caso típico de clima urbano, es decir de las modificaciones climáticas que resultan de la presencia de una ciudad y de las actividades que en ella tienen lugar. En comparación con los ambientes rurales circundantes, estas modificaciones son tanto de índole química, física y atmosférica (en la ciudad se incrementa el número de partículas contaminantes en suspensión, los núcleos de condensación y la mezcla de gases, y disminuye la insolación) como de índole propiamente climática (incremento del número de tormentas, incremento de la temperatura media anual -y la aparición consecuente de 'islas de calor' -, disminución de la humedad relativa -y la aparición de 'islas de sequedad' - y disminución relativa de los valores de viento).

La modificación del régimen térmico de las ciudades, cuando se traduce en un aumento de las temperaturas en los centros urbanos por contraste con su entorno rural, se conoce con el nombre de "isla de calor urbana" (Oke, 1987), y su cálculo se establece mediante la sencilla ecuación Taire

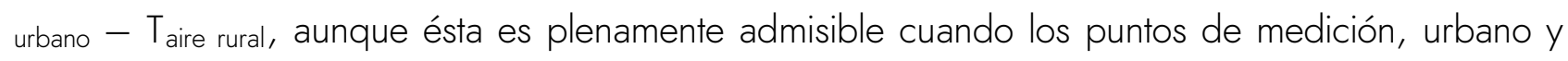
rural, en los que se basa esa diferencia reúnen unas mismas condiciones de altitud o distancia al mar, entre otras. El fenómeno se debe tanto a los cambios en el balance calorífico como a los 
cambios en el albedo, la radiación incidente o de los flujos de calor sensible y calor latente, así como a la producción interna de calor por los sistemas domésticos de calefacción y de refrigeración, el tráfico motorizado o las actividades industriales. Es por tanto lógico pensar que el incremento térmico que se manifiesta por estas causas ha de ser proporcional al tamaño de la ciudad. En este sentido, el mismo Oke $(1973,1987)$ establece una fórmula según la cual las diferencias térmicas máximas esperadas entre un entorno rural y uno urbano se dirimen en función de logaritmos del tamaño de la población $(P)$, que se cuantifica por el número de habitantes. Para el caso de grupos de ciudades europeas de tipo mediterráneo (compactas), diferentes a los grupos de ciudades de tipo anglosajón, más fragmentadas y extensas, la fórmula es la siguiente:

$$
I C U_{\text {máx }}=2,01 \log P-4,06 \quad r^{2}=0,74 \text { Error }= \pm 0,9^{\circ} \mathrm{C}
$$

De esta forma, para una ciudad como Palma, cuyo número de habitantes era en el año 2014 de 260.510 habitantes -es decir, excluyendo la población del municipio no estrictamente urbana-, la intensidad o IICU máxima esperada es de $6,8^{\circ} \mathrm{C}$.

A lo largo de un día típico y meteorológicamente estable se detectan teóricamente tres tipos de 'islas urbanas': una isla de calor nocturna, una isla de frescor matinal y una isla de calor diurna. La primera se empieza a producir poco después de la puesta del sol, cuando la temperatura debe haber empezado a disminuir, cosa que ocurre de manera natural en las áreas rurales y no ocurre en las áreas urbanas, que tienden a conservar en su interior, durante unas horas después de la puesta, el calor acumulado y generado por la misma actividad urbana. Esta inercia calórica da aquí unos registros de temperatura superiores a la temperatura registrada a la misma hora en el medio rural que rodea la ciudad, produciéndose unas diferencias de temperatura variables entre ambos medios, con un máximo entre las 23 y las 05, hora local. De esta manera, la diferencia de temperaturas suele perdurar hasta cerca del amanecer.

Por otro lado, después de la salida del sol -entre una y dos horas después-, la insolación comienza a hacer que aumente la temperatura del aire, cosa que se produce antes en el medio rural -cuya capacidad térmica es menor - que en el urbano, ya que los rayos solares no penetran fácilmente en el entramado de calles de la ciudad, sobre todo en los centros históricos de calles estrechas y mejor sombreadas. Se produce entonces una 'isla de frescor' urbana en virtud de la cual el aire de la ciudad es todavía más fresco que el del campo. Este efecto es más evidente en verano, y la isla de frescor remite sólo cuando hacia mediodía aparece la brisa diurna, igualándose las temperaturas del campo y de la ciudad. Aún en los casos en los que no opera la isla de frescor matinal, el contraste térmico definido por la isla de calor entre el campo y la ciudad es poco significativo, ya que la inercia calórica del medio urbano no muestra todos sus efectos hasta después de la puesta del sol, es decir, durante el ciclo nocturno. Finalmente, cuando la radiación solar logra alcanzar a lo largo de la mañana el suelo de la ciudad y se interrumpe la isla de frescor 
matutina, las temperaturas del medio urbano aumentan y superan a las de la periferia rural. Se forma entonces una isla de calor diurna, menos intensa que la nocturna, pues el medio urbano no ha llegado todavía a generar todo el calor que resulta de la actividad urbana.

Las investigaciones sobre clima urbano comienzan a desarrollarse en la década de los años 60 del pasado siglo, aplicadas sobre todo a ciudades centroeuropeas. En España sucede a partir de los años 80 del siglo pasado, con trabajos como los de López Gómez (1984) para la ciudad de Madrid o los de Moreno (1990 y 1994) para la de Barcelona. Por los años en los que se viene estudiando la fenomenología del clima urbano en el ámbito científico y geográfico español, son relativamente amplios los conocimientos que se tienen sobre el fenómeno, y numerosas las ciudades españolas estudiadas: Las Palmas de Gran Canaria (Hernández et al., 2001; Ruiz-Flaño et al., 2008), Zaragoza (Cuadrat et al., 1993), Granada (Montávez et al. 1998), Girona (Soler, 1998), Santa Cruz de Tenerife (Marzol et al., 1991; Dorta et al., 1992) o Alicante (Martínez, 2014), entre muchas otras. Sobrino y Oltra-Carrió (2012) han añadido conocimiento al que ya existe sobre el clima urbano de Madrid, y Martín-Vide et al. (2003) han hecho lo propio para la ciudad de Barcelona. Además, existen revisiones bibliográficas sobre las islas de calor de ciudades españolas, como las acometidas por Moreno $(1998,2007)$ y por Moreno y Serra $(2016)$, en este último caso ceñida sólo al caso de ciudades españolas de la vertiente mediterránea. En el ámbito de las Islas Baleares, Troya (2007) ha estudiado la isla de calor de Inca, en Mallorca, mientras que Troya y Capó (2012) han descrito el fenómeno en las poblaciones mallorquinas de Llucmajor, Campos, Pollença y Sa Pobla. Por su parte, Serra $(2007,2016)$ ha estudiado el caso de la isla de calor de la ciudad de Ibiza, así que las islas de Menorca y Formentera son las únicas en las que hasta el momento el fenómeno no ha sido investigado. Aunque los métodos empleados en estos estudios para identificar islas de calor pueden diferir -transectos móviles, pares de estaciones meteorológicas fijas que representan las áreas urbana y rural, obtención de la temperatura superficial mediante sensores remotos-, el método de los transectos ha sido utilizado con éxito en no pocos casos de ciudades no sólo españolas sino de todo el mundo: Padua, Italia (Busato et al., 2014); Tel-Aviv, Israel (Saaroni et al., 2000); Rancagua, Chile (Sarricolea et al., 2008); Sfax, Túnez (Dahech \& Beltrando, 2012) o Szeged, Hungría (Unger et al., 2001), entre otras.

En relación con la ciudad de Palma, el único precedente de un estudio de estas características se encuentra en la aportación de Ramis et al. (2002), en la que por vez primera se confirma instrumentalmente la existencia de una isla de calor urbana, con unas intensidades que oscilan entre los $4.0^{\circ} \mathrm{C}$ en el mes de diciembre y los $7.4^{\circ} \mathrm{C}$ en el mes de febrero, y cuyas mayores temperaturas se observan en el casco antiguo. Estos valores son los que se deducen a partir de seis campañas de campo realizadas entre 1998 y 1999, que cubren tres estaciones del año -la estación faltante es la de otoño-, y utilizando un método de medida de la temperatura en 51 
puntos de la ciudad, cuyas lecturas, sin ser completamente simultáneas, se igualaron por reducción a las 00 UTC.

En el caso de la presente investigación se ha pretendido, en primer lugar, actualizar y ampliar los resultados y las conclusiones de ese anterior trabajo. Para ello se ha optado por el método de los transectos o recorridos urbanos por unos circuitos previamente diseñados, en los que la toma de datos se hace de forma itinerante mediante un termómetro acoplado a un vehículo. La elección de Palma como una ciudad en la que se presume y se ha confirmado la existencia de una típica isla de calor, presenta algunos elementos de interés. Por una parte, se trata de una ciudad marítima, circunstancia que teóricamente propicia la moderación de las temperaturas -y por tanto de la eventual isla de calor-, sobre todo en unas condiciones de viento como las que produce un régimen de brisas marinas que en la bahía de Palma adquiere unas características prototípicas (Alomar Garau, 2012, 2013), ya que el viento, cuando supera ciertos valores críticos, desdibuja o elimina por completo los efectos térmicos que conlleva la existencia de un ecosistema urbano (Oke, 1987). Por otra parte, las diferencias de temperatura entre las áreas urbanas y las rurales crean diferencias locales de presión capaces de desencadenar el establecimiento de brisas que soplan desde el campo a la ciudad, alimentando en ella, en superficie, un tiro convectivo vertical. El origen genético -el calentamiento urbano- de este viento, y no geográfico - su procedencia desde el entorno rural- hace que Moreno (1997, p. 93) haya propuesto la denominación de "brisa urbana".

En segundo lugar, no hay trabajos sobre la isla de calor de Palma posteriores al año 2002, de manera que se hace necesario abordar de nuevo un estudio como este, cuyo objetivo es disponer de un conocimiento añadido y más completo del que ya se tiene sobre el fenómeno. En este sentido, el presente trabajo se presenta como un avance para un estudio general del clima urbano de Palma, estudio que puede ser completado todavía no sólo ampliando la base de datos temporal y espacial de temperaturas, y analizando aspectos que merecen una dedicación adicional, sino utilizando otros métodos y técnicas de análisis térmico de la superficie terrestre como los que proporciona la teledetección, y en concreto la imaginería infrarroja de los satélites de la serie NOAA dotados de un sensor AVHRR (Quereda et al., 2003).

\section{2 Área de estudio}

Palma constituye una ciudad mediterránea residencial, de servicios, administrativa y de negocios, flanqueada por núcleos turísticos, y cuyo término municipal, con un tamaño poblacional de 399093 habitantes en el año 2014 -último año del muestreo del presente trabajo- ocupa el octavo lugar de las ciudades de España en número de población. Según datos del Padrón publicados por el Instituto de Estadística de las Islas Baleares (IBESTAT), la ciudad propiamente dicha, cuyos límites podemos establecer en el semicírculo de la vía de circunvalación conocida 
como Vía de Cintura, sumaba ese mismo año 260510 habitantes, siendo sus características las de una ciudad media, según la categorización establecida por Precedo (1996).

Desde un punto de vista geográfico - unos $2^{\circ}$ de longitud Este y $39^{\circ}$ de latitud Norte-, Palma está ubicada al sur de la isla y su emplazamiento es plenamente marítimo, frente a una ancha bahía (Figura 1). Este hecho es relevante por los efectos que ocasiona en el clima de la ciudad, reduciendo la oscilación térmica diaria y moderando, por tanto, los extremos. Por otra parte, el régimen de vientos está condicionado por la presencia de un régimen de brisas regular (Alomar Garau, 2012, 2013), que en Palma opera con una dirección dominante del SO, es decir perpendicular a la línea de costa, y con unas velocidades que en época estival y a mediodía superan el umbral de los $5 \mathrm{~m} / \mathrm{s}(18 \mathrm{~km} / \mathrm{h})$.

De acuerdo con los datos que proporciona la Agencia Estatal de Meteorología (AEMET) relativos a los valores climatológicos normales, las condiciones climáticas de Palma, son, consideradas anualmente, las típicas de una latitud mediterránea, con una temperatura media anual de $18.2^{\circ} \mathrm{C}$, y con unos registros medios que se mueven entre los $11.9^{\circ} \mathrm{C}$ de enero y febrero, y los $26.2^{\circ} \mathrm{C}$ de agosto. La precipitación media anual es de 449 mm, y la humedad relativa media es alta, del 71 \%, que se explica por el contacto del emplazamiento con el mar. Estos datos, computados para el periodo 1981-2010, se refieren a la estación del Centro Meteorológico de la Delegación Territorial de la AEMET en las Islas Baleares, situada en el puerto de Palma. La comparación simple entre los valores de temperatura registrados en este puerto urbano, con los valores registrados por la estación de la AEMET en el aeropuerto de Son Sant Joan, en un emplazamiento rural y a unos 16 km por carretera del Centro Meteorológico, arroja una diferencia térmica entre ambas localizaciones de $1.7^{\circ} \mathrm{C}$ de temperatura media anual, a favor del puerto de Palma, diferencia que se eleva a los $2.3^{\circ} \mathrm{C}$ en los meses de invierno (diciembre, enero y febrero), y se reduce a $1.0^{\circ} \mathrm{C}$ en los meses estivales (junio, julio y agosto).

El marco urbano dentro del que opera la isla de calor totaliza un área de unos 18 km² (1800 hectáreas), y puede ser definido de la siguiente manera. El plano de la ciudad aparece organizado por dos tipos de tramas urbanas, más algunos barrios periféricos más o menos adosados a los principales ejes viarios que articulan interiormente el Ensanche (Figuras 2 y 3). La primera trama es la que constituye el sector de la Ciudad Antigua o Districte Centre, que se corresponde con la antigua ciudad preindustrial intramuros, con una superficie aproximada de 1,4 km² y una población, en el año 2014, de 22.846 habitantes. La Ciudad Antigua está constituida administrativamente por trece zonas estadísticas o barriadas: Puig de Sant Pere, Jaume III, Llotja-Born, Sant Jaume, Sant Nicolau, Cort, La Seu, Monti-Sion, La Calatrava, Es Sindicat, El Mercat, La Missió y Plaça dels Patins. Es Sindicat es la barriada más poblada (3900 habitantes), seguida de la de la Plaça dels Patins (3575 habitantes). La del Puig de Sant Pere es la menos poblada (480 habitantes). 
La Ciudad Antigua estuvo amurallada hasta el año 1902, y se divide en dos sectores principales, que son la Ciudad Alta y la Ciudad Baja, separadas por la vaguada por la que corría el antiguo cauce de Sa Riera -un torrent, según la denominación hidrográfica local-. Este antiguo curso, ya inactivo, aparece transformado actualmente en un eje viario que recorre la parte más baja de la ciudad, formado por la Rambla, la calle Unió y el Passeig des Born, y desemboca en la línea de fijación que constituye el lado oriental del puerto de Palma. Los históricos episodios de inundaciones provocaron el desvío forzoso del antiguo cauce de Sa Riera hacia una zona elevada de la ciudad el Passeig de Mallorca-, en la que se encaja el curso de agua actual, semi-permanente. A partir del año 1943 se acometió muy parcialmente un Plan de Reforma Interior, el Plan Alomar, con el que se abrieron vías más amplias (Jaume III, Passeig de Mallorca), edificadas siguiendo un criterio de unidad en lo referente a las alturas y el estilo. Sin embargo, buena parte del antiguo casco intramuros se caracteriza todavía por tener unas calles estrechas flanqueadas por edificios antiguos. En ellas se concentra la actividad comercial y en general administrativa de la ciudad, sin menoscabo de la función residencial.

Fue a partir del año 1901, con el llamado Plan Calvet, que se emprendieron los primeros procesos de expansión urbana extramuros, expansión que se materializó en el mencionado Ensanche. Éste se extiende desde las Avingudes o Avenidas, trazadas sobre el antiguo foso de las murallas que rodeaban la ciudad intramuros, hasta el primer cinturón de ronda de la Vía de Cintura. El Ensanche forma así una gran orla compacta que rodea circularmente la totalidad de la Ciudad Antigua. Si se contabilizan todas las zonas estadísticas comprendidas dentro de los límites que impone la Vía de Cintura, el Ensanche está constituido por un conjunto heterogéneo de treinta y cuatro barriadas: Cas Capiscol, Amanecer, L'Olivera, Son Oliva, Plaça de Toros, Hostalets, Son Fortesa (Sud), Son Canals, Can Capes, Son Gotleu, La Soledat (Nord), La Soledat (Sud), Nou Llevant, Foners, Pere Garau, Marquès de Fontsanta, Arxiduc, Bons Aires, Camp Redó, Es Fortí, Camp d'en Serralta, Santa Catalina, Es Jonquet, Son Cotoner, Son Dameto, Son Espanyolet, Son Dureta, Bellver, Sa Teulera, La Bonanova, Son Armadans, El Terreno, Cala Major y Porto Pi. Juntas, totalizan 237646 habitantes, con datos de 2014. Las más pobladas son las de Pere Garau (26 341 habitantes) y Bons Aires (18 257 habitantes), y la menos poblada la de Amanecer (529).

Mientras el plano del centro histórico es irregular, con calles estrechas y tortuosas, el plano del Ensanche es radioconcéntrico, con un "centro" en las Avenidas del que parten calles radiales, cortadas por otras que forman anillos en torno a ese centro. Los principales ejes viarios del Ensanche aparecen como una prolongación urbana de las principales carreteras de la isla, dando lugar a cinco ejes principales que dan salida a la ciudad hacia las poblaciones de Inca, Manacor, Sóller, Santanyí y Andratx. Estas mismas calles toman a veces los nombres de su procedencia o destino (Carretera de Manacor, Carretera de Valldemossa), y convergen radialmente hacia el centro geográfico de la ciudad. Los espacios intermedios entre los ejes quedan organizados 
mediante una tesela ortogonal y radial de manzanas y solares, constituyendo la zona más densamente poblada de la ciudad, y cuya función es esencialmente residencial, sin perjuicio de la función comercial. Ambas funciones se ejercen en fincas urbanas y edificaciones de aspecto disforme y alturas desiguales, en ocasiones desproporcionadas. Globalmente, la ciudad de Palma es asimétrica desde un punto de vista edificatorio, pues en el este está más edificada que en el oeste, sin menoscabo de las irregularidades edificatorias que encontramos en su interior.

Al entramado compacto de las dos zonas descritas le sigue una urbanización difusa periférica, en forma de suburbios o barrios residenciales, de índole postindustrial, que acaso complica la determinación de los límites morfológicos de la ciudad. Corresponden en general a espacios periurbanos y rururbanos en las inmediaciones de la Vía de Cintura y el litoral turístico, y aparecen con una cierta diversidad de tipologías urbanas: Son Cladera o Cas Capità, las zonas residenciales de Son Vida o Es Barranc, las áreas litorales de ocupación turística de Cala Major o Can Pastilla, o los núcleos de carácter semirural ligados a las zonas de regadío - pasadas o actuales- de Son Sardina, Sa Indioteria o Sant Jordi. Por último, en el tramo costero de la ciudad, frente a la catedral orientada al mar, destaca una Ronda Litoral construida a finales de la década de 1960 con el fin de comunicar el puerto de Palma con la parte de Poniente de la bahía de Palma, así como con el aeropuerto.

Figura 1. Situación del municipio y el núcleo urbano de Palma en el contexto geográfico de la isla de Mallorca, y su contexto mediterráneo y europeo

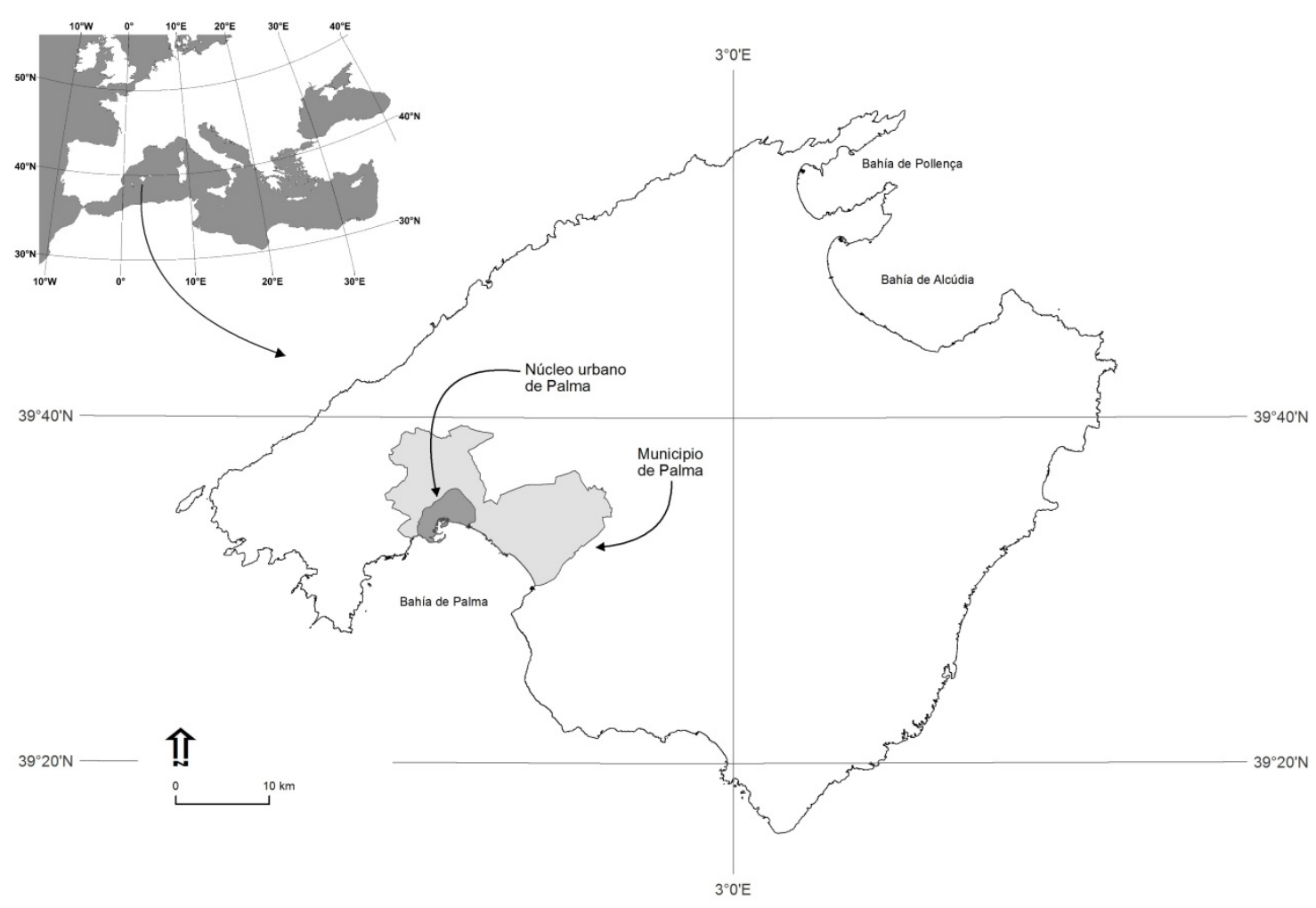

Fuente: elaboración propia 
Figura 2. Recorrido y numeración de los transectos en el municipio de Palma.

Edificaciones, curvas de nivel principales y barriadas principales

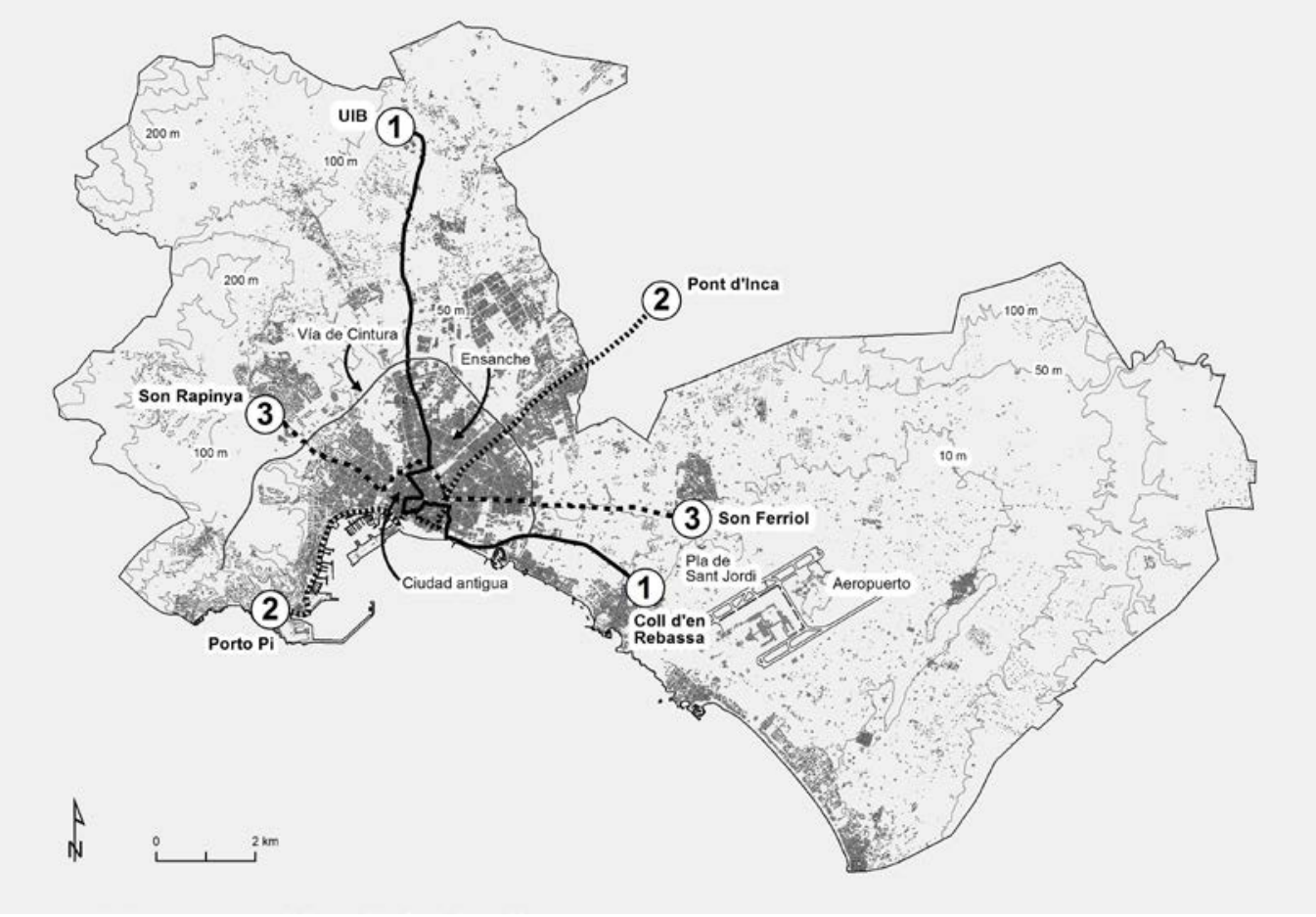

Fuente: elaboración propia

Figura 3. Recorrido parcial de los transectos sobre las principales barriadas de la Ciudad Antigua y el Ensanche de Palma

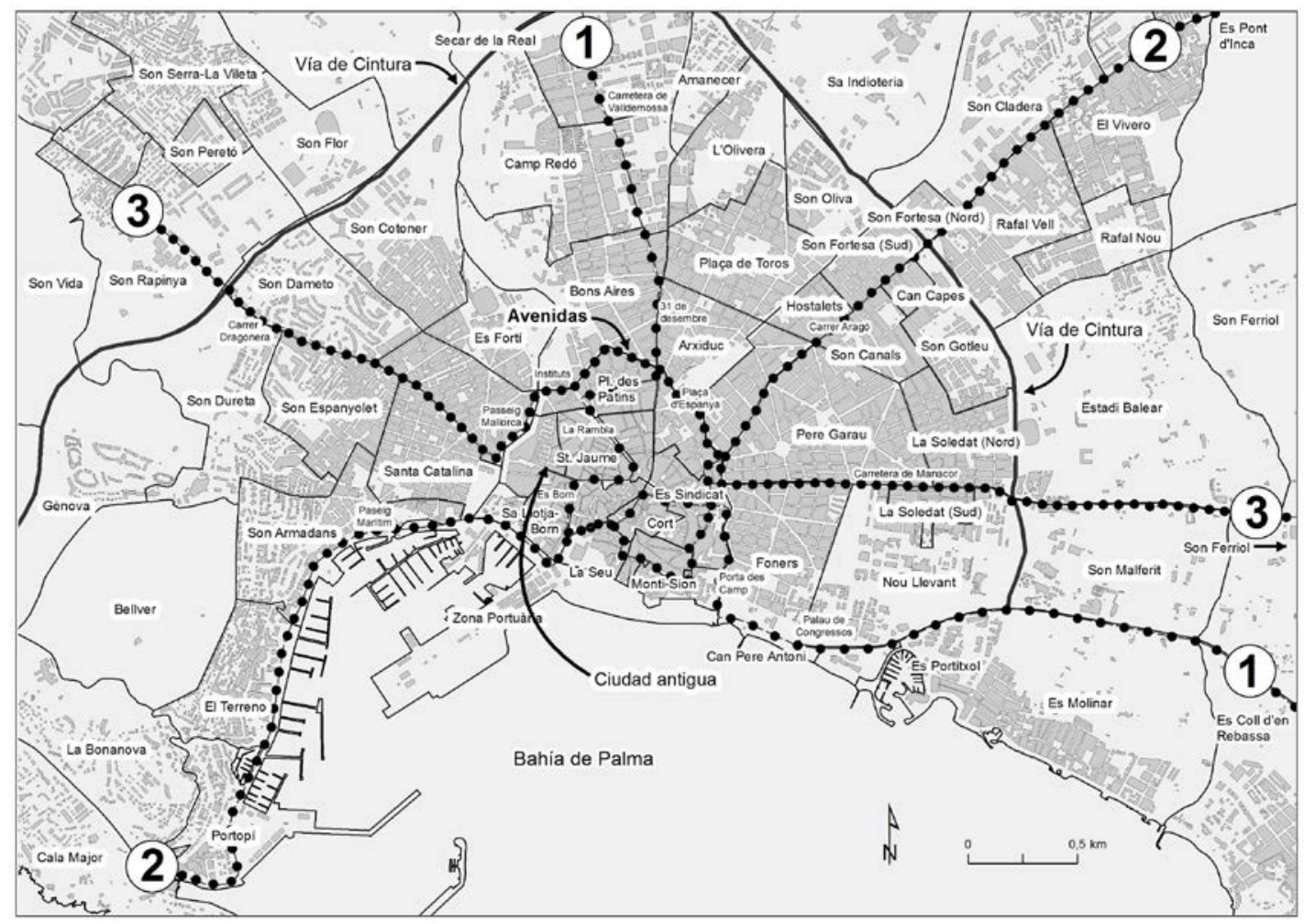

Fuente: elaboración propia 


\section{Metodología}

El presente estudio se ha realizado a partir de un conjunto organizado de mediciones de campo destinadas a la toma ordenada de datos térmicos, realizadas en las siguientes fechas: 6 de septiembre de 2013, 29 de noviembre de 2013, 27 de febrero de 2014 y 10 de julio de 2014. Las mediciones del día 6 de septiembre se iniciaron a las 06 horas, las 15 horas y las 23 horas, en horario local. Las mediciones del 29 de noviembre se realizaron sólo en horario nocturno, iniciándose a las 23 horas, también hora local. Las del 27 de febrero se hicieron en horario diurno y nocturno, iniciándose a las 06 horas y las 21 horas, respectivamente, mientras que las del 10 de julio se iniciaron a las 24, siempre en horario local. La selección del tramo horario central del 6 de septiembre, el de las 15 horas, se hizo con el objetivo de comprobar en lo posible los efectos de la brisa marina en la eventual manifestación de una isla de calor de carácter diurno. Las jornadas en las que se han realizado los muestreos son jornadas con unas condiciones ideales para la formación de un fenómeno de isla de calor, es decir noches o mañanas despejadas o prácticamente despejadas, con una situación sinóptica anticiclónica, en las que además es común que se produzcan fenómenos de inversión térmica en superficie.

La caracterización de la isla de calor urbana de Palma se ha acometido a partir del método de los transectos urbanos -tres en total-, lo que significa que la toma de datos se ha realizado de forma itinerante a lo largo de diferentes circuitos previamente definidos, y específicamente diseñados para dar cuenta de las diferencias de temperatura entre el ámbito rural que acordona la ciudad y el ámbito urbano propiamente dicho. Esto quiere decir que los circuitos tienen un origen en localizaciones típicamente rurales o al menos rururbanas, y desde ahí se dirigen hacia el centro de la ciudad, cubriendo, además, el sector marítimo de la misma. De esta manera se ha reparado en los diferentes usos del suelo, las distintas características viarias y edificatorias de la ciudad, y las variaciones geomórficas del terreno.

Los recorridos tienen diferentes longitudes, que totalizan $35 \mathrm{~km}$ y comprenden un total de 141 puntos de muestreo. El más largo tiene casi $15 \mathrm{~km}$ de longitud, y el más corto unos 9 km. Han sido numerados del 1 al 3 (Figura 2), y se acometieron siguiendo un orden horario, aunque no todos se hicieron en los mismos días ni en los mismos tramos horarios. En cualquier caso, se supuso que el tiempo de realización de tres transectos juntos, de menos de media hora cada uno, no superaría la hora y media, tiempo insuficiente para que entre la hora de inicio y la del final la temperatura en el centro de la ciudad hubiese cambiado de forma sustancial. Hay que decir que la radialidad de la planta urbana de Palma juega a favor de una toma efectiva y relativamente rápida de datos mediante transectos.

Los días de realización de los recorridos y sus horarios, así como los resultados numéricos de isla de calor obtenidos para cada uno de ellos, pueden consultarse en la Tabla 1. Los valores de IICU 
máxima se han obtenido mediante el cálculo de la diferencia entre el valor más alto de temperatura registrado en el ámbito urbano y el valor absoluto más bajo registrado en el ámbito rural -no siempre coincidente con el punto de inicio del recorrido, pero en cualquier caso siempre en la periferia rural-. A efectos de comparación de los datos recogidos se han elaborado gráficas que muestran la variación de la intensidad de la isla de calor urbana (IICU), medida en grados centígrados, desde el inicio de los transectos hasta el final de los mismos. En estas gráficas los datos de temperatura se han traducido a valores absolutos, reduciendo a 0 el valor de temperatura del punto de inicio del recorrido.

Para la toma de datos se utilizó un termohigrómetro digital Zelsio P330, cuya resolución es, para la temperatura, de $0,1^{\circ} \mathrm{C}$, y para la humedad, del $0,1 \%$, siendo el rango de medidas de temperatura de $-40^{\circ} \mathrm{C}$ a $+70^{\circ} \mathrm{C}$, y de humedad del $0 \%$ al $99 \% \mathrm{rh}$. El termohigrómetro incluye una sonda, que para una toma eficiente de los datos fue acoplada en el techo del vehículo dispuesto para la ocasión.

\section{Resultados}

\section{1 Transecto 1}

El transecto 1 tiene una longitud de 14,5 km y comprende 58 puntos de muestreo. En términos espaciales, une el campus de la Universitat de les Illes Balears (UIB) con los terrenos cercanos a la barriada periférica del Coll d'en Rebassa y del polígono de Mercapalma, antesala del aeropuerto de Son Sant Joan, situado en el llano rural del Pla de Sant Jordi. De esta manera, el transecto contiene información térmica del entorno rural al norte y al este del núcleo urbano de Palma, además de la información concerniente a este mismo núcleo. Se ha recorrido en un total de siete ocasiones en verano (julio y septiembre), otoño e invierno (noviembre y febrero), y en horario de mañana y de noche, si se exceptúa el recorrido que se realizó el 6 de septiembre a mediodía (las 15.00, hora local). Es en este transecto donde pueden identificarse con mayor confianza las especiales condiciones térmicas que se suponen en el casco antiguo de Palma y su Ensanche, y su presunto contraste con las de la periferia rural, ya que el transecto es el más completo y recorre 2,8 $\mathrm{km}$ de arterias que pertenecen estrictamente a la Ciudad Antigua.

La variación de la temperatura a lo largo del recorrido es la que cabe esperar cuando se abandona el medio rural y se alcanza un medio plenamente urbano, cuyo límite por el norte lo constituye la zona del centro comercial y de ocio Ocimax, a pocos metros de la Vía de Cintura, y cuyo límite por el este puede establecerse en el nuevo Palau de Congressos, punto de partida de la autopista de Llevant que conduce al aeropuerto de Son Sant Joan. La isla de calor aparece claramente manifestada tanto a primera hora de la mañana como por la noche (Figura 4 y Tabla 1). En verano (julio y septiembre), su intensidad alcanza valores entre $4.1^{\circ} \mathrm{C}$ y $4.9^{\circ} \mathrm{C}$, siendo los puntos de la 
ciudad en los que esto sucede las calles interiores del casco antiguo -en concreto, en la barriada de Es Sindicat-. Los puntos más fríos están normalmente en el campus de la Universitat de les Illes Balears, lugar de inicio del recorrido, y en la carretera que une este campus con la ciudad, a la altura del Centro Penitenciario, en la zona del Secar de la Real. El campus universitario, siempre más frío que la ciudad - si se exceptúa el mediodía estival del día 6 de septiembre-, se encuentra en un entorno rural a una cota de 85 metros sobre el nivel del mar, de manera que la influencia de la altitud podría parece inicialmente un factor a considerar. En cuanto a las mediciones otoñales e invernales de noviembre y febrero, la IICU máxima oscila entre los $3.9^{\circ} \mathrm{C}$ y los $5.8^{\circ} \mathrm{C}$, siendo dos los puntos principales en los que la diferencia entre el mínimo rural y el máximo urbano es máxima: por una parte, en la misma zona -Es Sindicat- en la que aparecían los máximos encontrados durante las mediciones efectuadas en verano, y por otra, en la ronda litoral a la altura del nuevo Palau de Congressos.

Cabe señalar que la amplitud térmica entre el punto en el que se ingresa definitivamente en la ciudad -el centro de ocio Ocimax- y el punto en el que se sale de ella -la Porta des Camp- es relativamente alta en ciertas fechas $\left(3.1^{\circ} \mathrm{C}\right.$ en la de la mañana de septiembre y la noche de noviembre), y pequeña en otras (1. $1^{\circ} \mathrm{C}$ en la noche de febrero). Esto es independiente de que, en ocasiones, se manifiesten cambios bruscos de temperatura entre un punto del muestreo y el siguiente, pues en el interior de la ciudad se han encontrado variaciones entre puntos vecinos de hasta $1^{\circ} \mathrm{C}$.

Sea como sea, los valores de temperatura obtenidos al inicio del recorrido son siempre más bajos que los valores obtenidos en el interior de la ciudad. Sin embargo, el aumento de temperaturas consignado no es uniforme, sino que se interrumpe transitoriamente cuando el circuito atraviesa pequeñas depresiones o elevaciones del terreno. En el caso de este transecto, estas discontinuidades se ponen de manifiesto en los mismos puntos en los cuatro días de medición considerados. El primero de ellos, muy importante, y coincidiendo con una depresión del terreno, se encuentra en el corto tramo de carretera entre la rotonda del hospital de Son Espases y la rotonda del centro de ocio Ocimax, tramo en el que a la altura del Centro Penitenciario la temperatura disminuye abruptamente respecto a la muestra precedente, con una diferencia de hasta $2.3^{\circ} \mathrm{C}$. La temperatura vuelve a ascender enseguida que se deja atrás esa segunda rotonda. La segunda perturbación de interés la encontramos dentro de la ciudad, en el tramo comprendido entre la Plaça dels Patins y el final de la Rambla, pues el promedio de temperaturas de los puntos de muestreo en este tramo es siempre inferior a la temperatura del punto de muestreo inmediatamente anterior al de la Plaça dels Patins. Así, entre esta plaza y el punto precedente se han registrado cambios súbitos de hasta $1^{\circ} \mathrm{C}$. El descenso térmico en este tramo queda bien explicado por el ensanchamiento de la vía, la ampliación de la superficie pavimentada con baldosas 
y no con asfalto, y un aumento considerable del arbolado -en la Rambla, una doble hilera de plataneros de sombra (Platanus hispanica)-.

Cuando se abandona el tramo relativamente 'frío' de la Rambla, las temperaturas presentan una tendencia al alza, aunque ligera. Así, los tramos siguientes, la calle de la Unió y el Passeig des Born -una vía bien arbolada y ancha- son la continuación natural de la Rambla, y sin embargo la temperatura se presenta unos decimales más elevada, contrariamente a lo que cabría esperar en una arteria de estas características. El factor de la motorización debe de jugar aquí un papel, pues efectivamente tanto en la calle Unió como en el Passeig des Born la densidad de tráfico se antoja mayor que en la Rambla. Es cuando se abandona esta zona y se asciende hacia Cort, centro de la Ciudad Antigua, que la temperatura aumenta decididamente, para alcanzar sus valores máximos en las arterias de menor entidad de la antigua ciudad intramuros. Si bien el tráfico rodado no tiene apenas significación en esta zona, en la que además los materiales de construcción utilizados son sobre todo de mampostería de piedra arenisca -marès, según la denominación local_, el aumento térmico se explica por la estrechez de las calles y su corto recorrido, unida a la altura relativa de los edificios, características geométricas que reducen el factor de visión del cielo y por tanto impiden una pérdida efectiva del calor por irradiación. Así, dependiendo de la fecha de medición, las IICU máximas $\left(5.8^{\circ} \mathrm{C}\right.$ en la noche de noviembre y la mañana de febrero, $4.9^{\circ} \mathrm{C}$ en la noche de julio y $4.7^{\circ} \mathrm{C}$ en la mañana de septiembre) se alcanzan tanto en las inmediaciones de la Plaça Major, es decir en la barriada de Es Sindicat, como en el límite oriental de esta misma barriada, antes de alcanzar la avenida Gabriel Alomar Villalonga. A partir de la Porta des Camp las temperaturas comienzan a descender, tan pronto como se está abandonando la ciudad, aunque se advierte un repunte térmico frente al mar, que merece la siguiente explicación.

En la noche de febrero la isla de calor presenta una distribución espacial más dilatada, pues los valores máximos aparecen tanto en la calle 31 de Desembre, poco antes de alcanzar las Avenidas, como en Es Portitxol, junto al mar, ya fuera de la ciudad. En esta fecha, entre estos dos focos los valores de intensidad absoluta de isla de calor oscilan poco, $1.1^{\circ} \mathrm{C}$. La medición de la noche de julio también es bifocal, pues se identifica un foco en la barriada de Es Sindicat, en el que la diferencia es de $4.9^{\circ} \mathrm{C}$ respecto al valor mínimo del campo, diferencia que también aparece frente a la Platja de Can Pere Antoni. Entre ambos focos la oscilación térmica es de sólo $0.8^{\circ} \mathrm{C}$. Sea como sea, el efecto de isla de calor parece que se extiende en ciertos casos hasta el mar, frente a la playa urbana de Can Pere Antoni. Se trata de un punto relativamente alejado del centro de la ciudad. Estos máximos marítimos, laterales, encuentran una explicación en las dimensiones de los edificios alrededor del sensor, factores que retardan el esperado enfriamiento del aire en esta zona una vez que se ha empezado a salir del centro de la población. Además, se trata de un punto con mucho suelo asfáltico, así como un sitio en el que el tráfico motorizado efectúa paradas por 
indicación de semáforos, circunstancia que tiene efectos inmediatos en el sensor, que acusa un aumento de la temperatura concretado en ese punto.

Finalmente, las temperaturas al final del recorrido, en el entorno rural al norte del Coll d'en Rebassa, son siempre superiores a las de su inicio en el campus de la Universitat de les Illes Balears o su cercanías, cosa que se explica porque la muestra del Coll d'en Rebassa está recogida en una autopista, y además está afectada no sólo por una urbanización cercana, sino también por la proximidad al mar y porque la cota altimétrica es mucho menor, de apenas 10 metros sobre el nivel del mar.

Figura 4. Perfiles térmicos $\left({ }^{\circ} \mathrm{C}\right)$ del transecto número 1 (Universitat de les Illes Balears-Coll d'en Rebassa), para los días y hora de inicio indicados en la leyenda

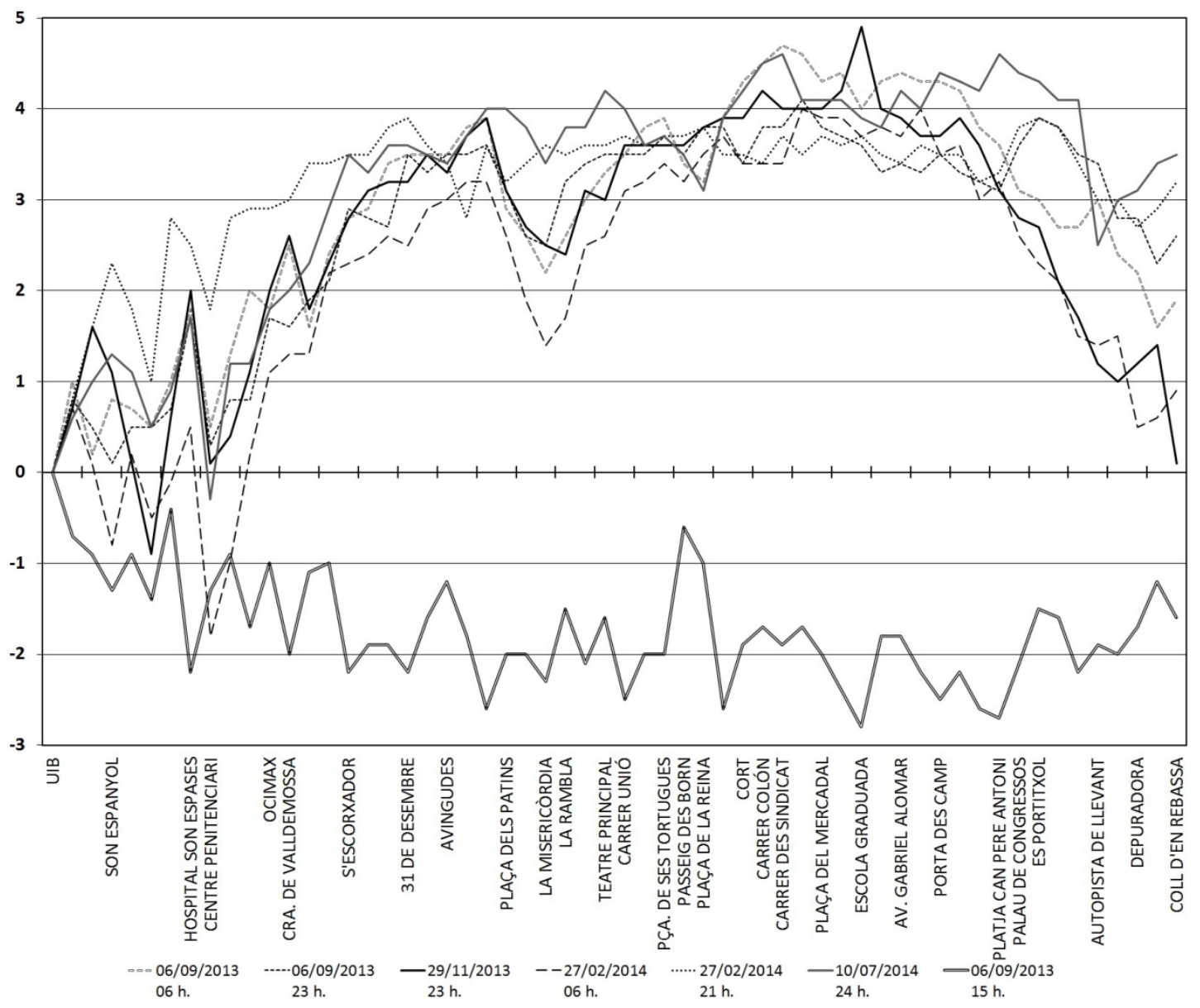

Fuente: elaboración propia

Hay que mencionar también que el transecto número 1 incluyó una medición estival, el 6 de septiembre, a una hora cercana al mediodía solar (las 13 UTC), cuyo resultado fue la identificación de una isla de frescor urbana (Figura 4), aunque retrasada en relación a la teórica isla de frescor matinal que ha de producirse una o dos horas después de salir el Sol. Así, en el interior de Palma la temperatura se reveló a esa hora más fría que en las afueras. La diferencia no fue grande, de 
$2.8^{\circ} \mathrm{C}$, pero el caso es que pasado el mediodía la temperatura era más alta en el campus universitario $\left(30^{\circ} \mathrm{C}\right)$ que en la barriada de Es Sindicat $\left(27.2^{\circ} \mathrm{C}\right)$. Es, sin embargo, una diferencia suficiente para que no pueda soslayarse el hecho de que a mediodía, en verano y en ausencia de brisa, el centro de Palma es susceptible de ser ligeramente más frío que el campo, siendo el sector más fresco el mismo en el que aparecían las burbujas más cálidas cuando describíamos el fenómeno inverso de isla de calor. Que sea esta la barriada con el foco más fresco se explica porque los rayos solares no han alcanzado plenamente el interior de sus calles, más estrechas y por tanto mejor sombreadas.

\subsection{Transecto 2}

El transecto 2 tiene una longitud de 11,2 km y comprende 47 puntos de muestreo. Los datos obtenidos corresponden a las mediciones diurna y nocturna del 27 de febrero, así como a las mediciones nocturnas del 29 de noviembre y del 10 de julio. El transecto une la localidad del Pont d'Inca a la altura del aeródromo de Son Bonet (todavía en territorio del municipio colindante de Marratxí) con la zona portuaria de Porto Pi, al oeste de la ciudad. Su diseño responde a los siguientes dos objetivos: el primero, verificar si la transición térmica que se produce entre un entorno periférico semiurbanizado y el núcleo plenamente urbanizado de la ciudad, es una transición más suave que la que se presume entre un entorno plenamente rural y ese mismo núcleo. El segundo objetivo es comprobar la influencia del mar en la variación térmica del recorrido, ya que el transecto, una vez que se abandona el centro de la ciudad, se dirige hacia el frente marítimo de Palma, y desde ahí recorre en su totalidad la larga ronda -el Passeig Marítim- que recorre la zona marítima y portuaria de la ciudad, hasta su remate en la base naval de Porto Pi.

El perfil térmico a lo largo del transecto sigue en lo fundamental un patrón análogo al que se ha descrito para el transecto número 1. Es decir, se observa un aumento de la temperatura del aire a medida que penetramos en la trama urbana del centro de Palma, y un descenso cuando se abandona este centro (Figura 5 y Tabla 1). El Pont d'Inca, origen del transecto, es un núcleo satélite periurbano con edificios de menor entidad, y cuya solución de continuidad se halla en la calle Aragó, uno de los ejes del Ensanche más transitados de Palma y de mayor altura edificatoria. A partir de la toma del primer dato las temperaturas presentan un incremento relativamente uniforme, incremento que es de hasta $2.2^{\circ} \mathrm{C}$ una vez que se franquea la Vía de Cintura por el noreste, siempre en la calle Aragó. Poco después se alcanzan las Avenidas, y a partir de la Porta de Sant Antoni el itinerario transcurre por la Ciudad Antigua. El aumento de la temperatura entre el primer punto de la muestra y la misma Porta de Sant Antoni parece ser tanto mayor cuanto más frío es el ambiente, pues en la noche del 29 de noviembre, más fría que la del 27 de febrero, la diferencia entre ambos puntos fue de $4.3^{\circ} \mathrm{C}$, mientras que en la noche de febrero la diferencia fue de $0.7^{\circ} \mathrm{C}$. 
Llama la atención las diferencias en los resultados de las cuatro mediciones realizadas para este transecto. Mientras la IICU en la noche del 29 de noviembre fue de $4.5^{\circ} \mathrm{C}$, en las noches de febrero y de julio la variación de las temperaturas se tradujo en una isla de calor poco definida y con unos valores de intensidad máxima poco significativos, de $1.4^{\circ}$ y $2.2^{\circ} \mathrm{C}$, respectivamente. Además, la isla de calor adoptó un carácter mesetario en la medición nocturna del 27 de febrero, cosa que se puede atribuir a la temperatura del mar -el transecto número 2 es el más marítimo de los tres-, que en ese mes se encuentra en su extremo mínimo, 'enfriando' la burbuja cálida e impidiendo su desarrollo pleno (según datos del Instituto Español de Oceanografía, la temperatura media de la superficie del mar en el archipiélago balear es de $13.8^{\circ} \mathrm{C}$ en invierno, notablemente más baja que la de verano, de $24.8^{\circ} \mathrm{C}$ ). En cualquier caso, interesa destacar que los valores de ॥CU máxima se alcanzan en puntos de la Ciudad Antigua, de manera parecida a como ocurre en el caso del transecto número 1, si se exceptúa la medición de la noche del 27 de febrero, en que la IICU adquiere sus mayores valores (hasta $1.4^{\circ} \mathrm{C}$ ) en puntos concretos del Ensanche palmesano y del Passeig Marítim, aunque la amplitud térmica es en este caso ciertamente pequeña. Así, menos en esa medición, la IICU es mayor en las barriadas de Monti-Sion y Es Sindicat.

Figura 5. Perfiles térmicos $\left({ }^{\circ} \mathrm{C}\right.$ ) del transecto número 2 (Es Pont d'Inca-Porto Pi), para los días y hora de inicio indicados en la leyenda

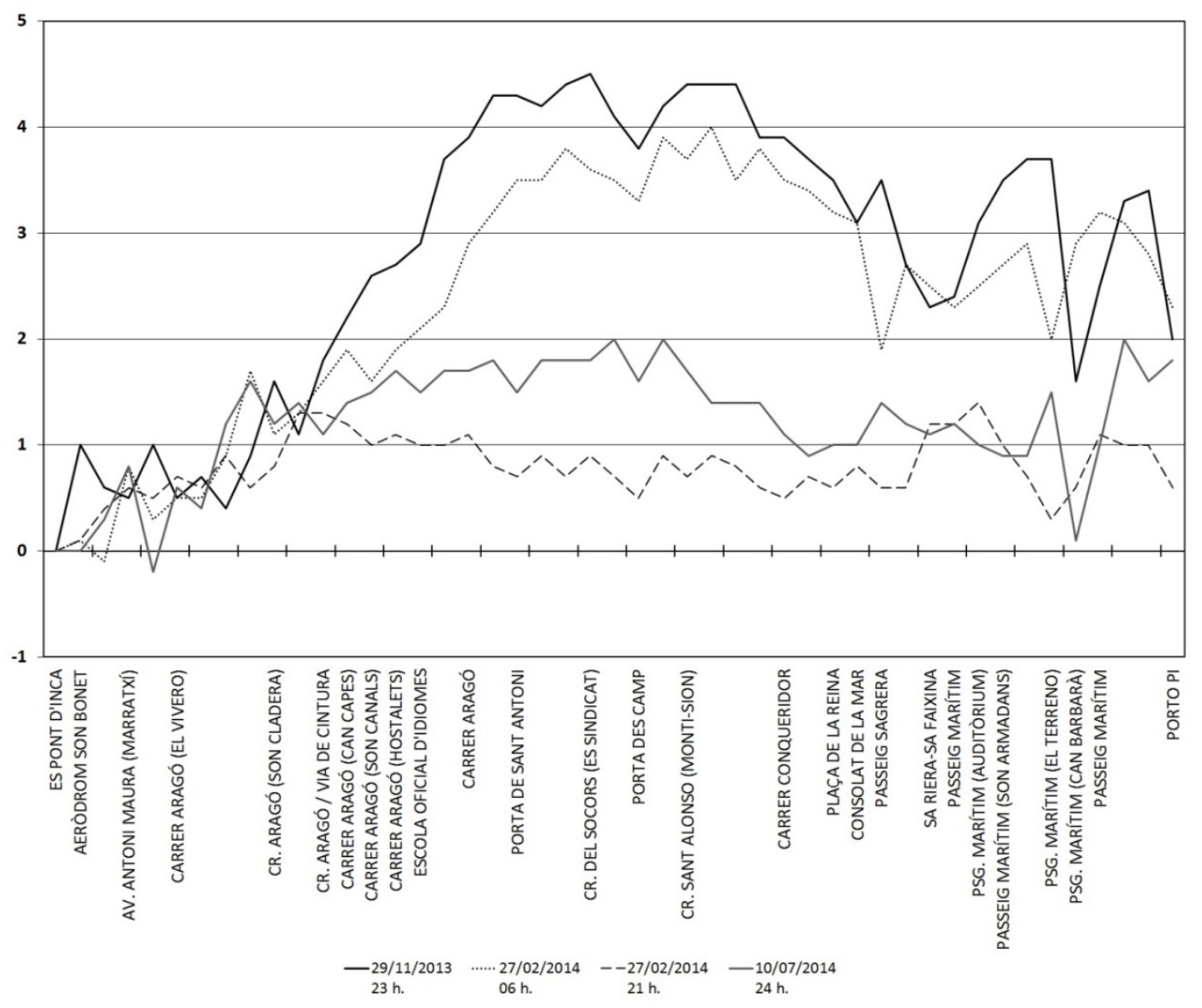

Fuente: elaboración propia 
Ya que el transecto número 2 se diseñó de manera que se pudiese comprobar la influencia del mar en el régimen térmico de la ciudad, la parte final del circuito recorre 3,8 km de frente litoral, entre el Passeig de Sagrera y Porto Pi. Una vez que se abandona el centro de la ciudad y se alcanza la zona portuaria, los valores de temperatura vuelven a disminuir y el efecto de isla de calor parece disolverse. Esto ocurre normalmente en el primer tramo del itinerario costero (en el Consolat de Mar y el Passeig de Sagrera), mejor equipado de vegetación que el tramo siguiente, y en donde la fachada opuesta al mar presenta un volumen edificado mucho menor. De hecho, la temperatura vuelve a aumentar tan pronto como a un lado del recorrido asoman los altos edificios de apartamentos y hoteles que caracterizan parte del paisaje urbano del Passeig Marítim (en concreto, los alrededores del Auditòrium), hasta el punto de que es en el sector costero de las barriadas de Son Armadans y El Terreno donde en la noche del 27 de febrero se alcanzan nuevos valores de IICU máxima, que se interrumpen sólo cuando se circula junto a la dársena de Can Barbarà. También cabe considerar la cercanía del gran bosque de Bellver, básicamente un denso pinar que tendería a atenuar el enfriamiento nocturno en esta zona de la ciudad.

\subsection{Transecto 3}

El transecto 3 tiene una longitud de 9,3 km y comprende 36 puntos de muestreo. Recorre de este a oeste, conectando los terrenos inmediatos a la localidad periférica de Son Ferriol, al este, con la carretera que conduce a la barriada igualmente periférica de Son Rapinya, al oeste. Esta conexión se realiza atravesando el centro de Palma por las denominadas Avenidas, es decir circunvalando la Ciudad Antigua intramuros, sin adentrarse en ella. Las Avenidas constituyen uno de los sectores de la ciudad que soportan más tráfico rodado y donde los edificios son altos. La misión del transecto no se reduce a detectar la existencia del fenómeno de isla de calor, sino que además tiene el propósito de observar si en el sector oriental de la ciudad las temperaturas son más frías que en el sector occidental. Esta hipótesis se basa en el hecho de que el sector oriental se encuentra adosado al llano del Pla de Sant Jordi, ocupado en buena parte por tierras de cultivo, además del amplio conglomerado aeroportuario y otras infraestructuras del sector terciario. En este llano se ha constatado la existencia de una circulación nocturna de corrientes catabáticas de aire procedentes de las pequeñas colinas circundantes, que en su descenso enfrían la zona (Jiménez et al., 2006). Presumiblemente, este enfriamiento lo acusan las barriadas orientales de Palma, aunque lo harían a primera hora de la mañana y con cielos despejados, cuando la masa de aire frío reposa ya sobre el llano, produciendo nieblas y fenómenos de inversión térmica.

De acuerdo con los datos recabados, sólo en la noche del 27 de febrero, con una IICU débil, de $2.4^{\circ} \mathrm{C}$, se identifica un fenómeno de isla de calor bien definido (Figura 6 y Tabla 1), entendiendo con ello la evidencia instrumental de unas temperaturas más bajas tanto en el origen como en el final del recorrido, y más altas en el interior de la ciudad. En las otras dos mediciones también se manifiesta el fenómeno, pero su estructura es menos organizada. 
La hipótesis planteada aparece confirmada por las muestras recogidas, pues la variación de las temperaturas no es la misma en el lado de Son Ferriol, más frío, que en el de Son Rapinya, que parece comportarse térmicamente como un medio urbano, y en donde, por tanto, las temperaturas no siempre descienden según lo esperado. Esta circunstancia se produce en las mediciones de la mañana de febrero y la noche de noviembre, pero no en la medición de la noche de febrero, cuando la isla de calor presenta unas características radioconcéntricas típicas. Cabe centrar la atención, por tanto, en esta última toma de datos.

La misma Figura 6 permite apreciar el gradiente térmico positivo que en la noche de febrero se produce a poco de iniciar el recorrido. La temperatura aumenta resueltamente en consonancia con los cambios ambientales que induce la urbanización. El ingreso en un medio propiamente urbano tiene lugar abruptamente cuando se ha atravesado por el este la Vía de Cintura y se llega, ya en la carretera de Manacor, a la barriada de La Soledad, momento en el que ya se alcanza la primera máxima diferencia $\left(2.4^{\circ} \mathrm{C}\right)$ entre la temperatura mínima y máxima del transecto. A partir de aquí la oscilación térmica es pequeña, sujeta sólo a las variaciones ocasionadas por el paso del sensor junto a determinados focos de emisión de calor, o bien de su atenuamiento debido a la presencia de vegetación o de un ensanchamiento notable de la vía. Así, se da la circunstancia, identificada en las tres mediciones realizadas para este transecto, de que la arteria urbana de la Carretera de Manacor, en donde la densidad de edificaciones y de tráfico es relativamente alta, es donde se produce un cambio notorio de temperaturas respecto al régimen térmico de las afueras de la ciudad, pero en esta misma arteria, cuando se deja atrás la barriada de La Soledad y nos dirigimos hacia el centro de la ciudad, los registros de temperatura disminuyen ligeramente, coincidiendo con un claro ensanchamiento de la vía. Cuando se alcanza el semicírculo de las Avenidas, el comportamiento de las temperaturas a lo largo de esta ronda interior es el esperado. En todas las mediciones los registros de temperatura son aquí uno de los más altos. Por ejemplo, en la toma de datos hecha la noche de noviembre, con una IICU de $4.8^{\circ} \mathrm{C}$, las mayores diferencias térmicas con la zona rural de Son Ferriol se alcanzan tanto en el tramo entre la Porta de Sant Antoni y la Vía Alemanya -lo que incluye la Plaça d'Espanya-, como en la calle Dragonera, poco antes de la salida de la ciudad por el oeste.

En las tres mediciones del transecto número 3, el punto de inflexión más importante se encuentra en la intersección de las Avenidas (en concreto, la Via Alemanya) con la vaguada de la Rambla (frente a los llamados Institutos), en donde la temperatura acusa una caída notoria. No es sólo porque el sensor se muestra sensible a la vaguada, sino también porque en este sector el terreno es más abierto y muy próximo al nuevo cauce de Sa Riera. Precisamente cuando el recorrido alcanza Sa Riera y sigue su mismo curso por el Passeig de Mallorca, se descompone por completo la isla de calor, pues la diferencia entre los valores de temperatura consignados en las Avenidas y los consignados en el Passeig de Mallorca, un eje viario y de paseo, llega a ser de $2.5^{\circ} \mathrm{C}$. Este 
descenso térmico, también detectado en el trabajo de Ramis et al. (2002), no es más que un fiel reflejo de la entrada de aire frío por el cauce de Sa Riera - de unos 25 metros de sección transversal-, que opera como eje de enfriamiento por el drenaje catabático dirigido por el mismo cauce, hasta casi la orilla del mar.

Como se ha señalado, en dos de las mediciones de este transecto la ICU aparece muy desorganizada, sobretodo en el extremo oeste del recorrido. La causa de este desarreglo se encuentra en las condiciones ambientales urbanas que parecen darse en ese extremo, es decir en los ejes viarios que conducen a Son Rapinya, punto final del recorrido. Así, una vez que se abandona el foco frío del Passeig de Mallorca las temperaturas vuelven a aumentar, siguiendo la lógica propia de un ambiente todavía urbano, pero no empiezan a disminuir, como sería razonable, en la calle Dragonera, antesala del final de la ciudad. Al contrario, en este sector el efecto de isla de calor se mantiene relativamente vigente, incluso cuando se alcanza el Camí de Son Rapinya, al oeste de la ciudad, en donde los registros de temperatura se asemejan a los obtenidos en las Avenidas (Porta des Camp y Plaça d'Espanya).

Figura 6. Perfiles térmicos $\left({ }^{\circ} \mathrm{C}\right)$ del transecto número 3 (Son Ferriol-Son Rapinya), para los días y hora indicados en la leyenda

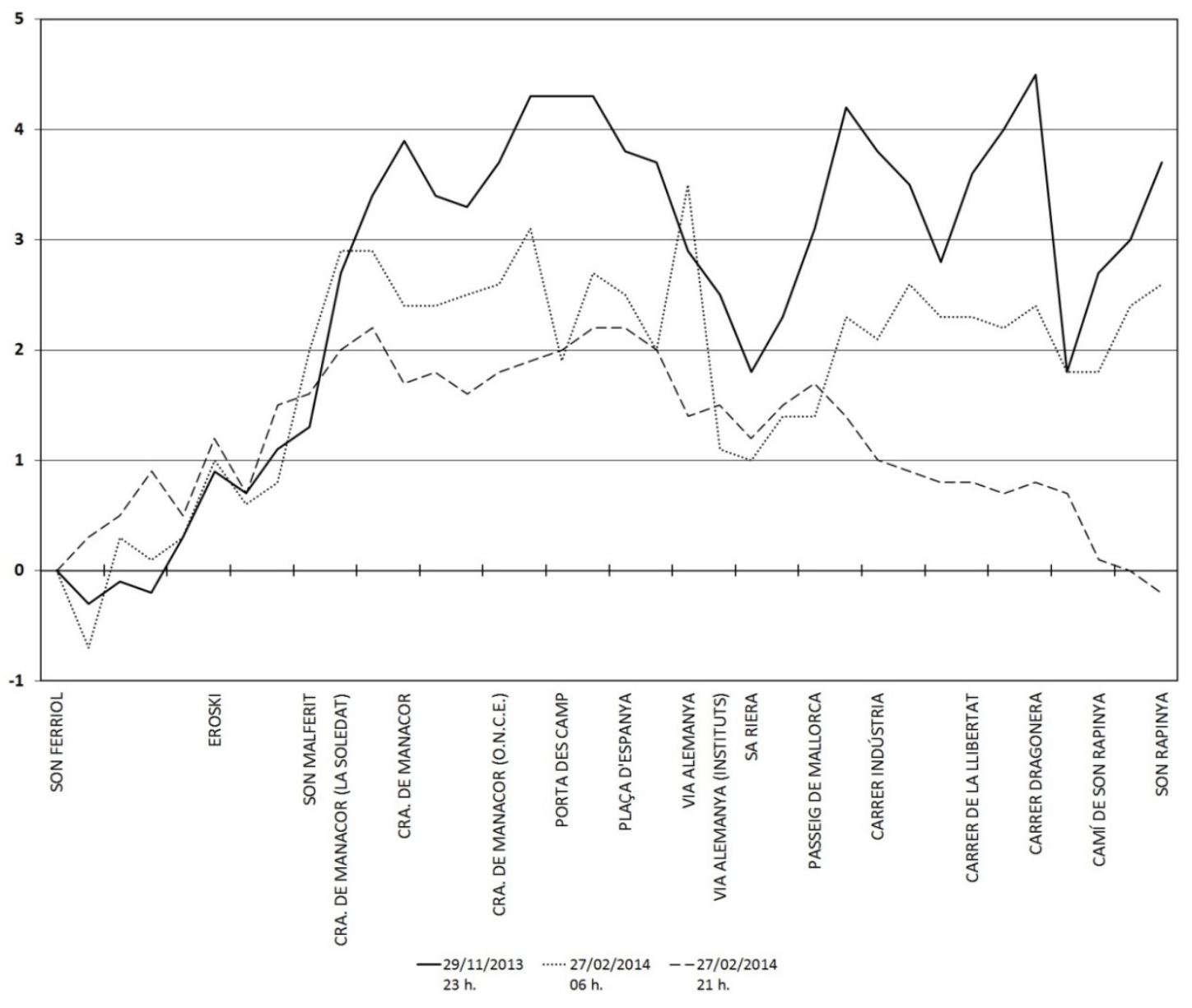

Fuente: elaboración propia 
Tabla 1. Resumen de resultados de la intensidad máxima y media de la ICU de Palma para cada transecto, y valores térmicos máximos y mínimos registrados durante los recorridos

\begin{tabular}{|c|c|c|c|c|c|c|c|c|}
\hline & TRANSECTO & $\begin{array}{l}\text { Long. } \\
(\mathrm{km})\end{array}$ & Fecha & $\begin{array}{l}\text { Hora local } \\
\text { de inicio }\end{array}$ & $\begin{array}{l}\text { Intensidad máx. } \\
\text { de la ICU }\left({ }^{\circ} \mathrm{C}\right)\end{array}$ & $\begin{array}{c}\text { Intensidad } \\
\text { media } \\
\text { de la ICU }\left({ }^{\circ} \mathrm{C}\right)\end{array}$ & $\begin{array}{l}T^{a} \text { máx. } \\
\left({ }^{\circ} \mathrm{C}\right)\end{array}$ & $\begin{array}{l}{ }^{\mathrm{a}} \text { mín. } \\
\left({ }^{\circ} \mathrm{C}\right)\end{array}$ \\
\hline \multirow{7}{*}{1} & \multirow{7}{*}{$\begin{array}{l}\text { UIB - } \\
\text { Coll d'en Rebassa }\end{array}$} & \multirow{7}{*}{14,5} & 6 de septiembre & 06.00 & 4.7 & \multirow[t]{7}{*}{ (10 } & 22.9 & 18.2 \\
\hline & & & 6 de septiembre & 15.00 & $\begin{array}{c}-2.8 \\
\text { Isla de Frío }\end{array}$ & & 30.0 & 27.2 \\
\hline & & & 6 de septiembre & 23.00 & 4.1 & & 25.6 & 21.5 \\
\hline & & & 10 de julio & 24.00 & 4.9 & & 24.5 & 19.6 \\
\hline & & & 29 de noviembre & 23.00 & 5.8 & & 9.8 & 4.0 \\
\hline & & & 27 de febrero & 06.00 & 5.8 & & 8.9 & 3.1 \\
\hline & & & 27 de febrero & 21.00 & 3.9 & & 13.5 & 9.6 \\
\hline \multirow{4}{*}{2} & \multirow{4}{*}{$\begin{array}{l}\text { Pont d'Inca - } \\
\text { Porto Pi }\end{array}$} & \multirow{4}{*}{11,2} & 10 de julio & 24.00 & 2.2 & \multirow{4}{*}{3.1} & 23.5 & 21.3 \\
\hline & & & 29 de noviembre & 23.00 & 4.5 & & 8.8 & 4.3 \\
\hline & & & 27 de febrero & 06.00 & 4.1 & & 9.0 & 4.9 \\
\hline & & & 27 de febrero & 21.00 & 1.4 & & 13.4 & 12.0 \\
\hline \multirow{3}{*}{3} & \multirow{3}{*}{$\begin{array}{l}\text { Son Rapinya - } \\
\text { Son Ferriol }\end{array}$} & \multirow{3}{*}{9,3} & 29 de noviembre & 23.00 & 4.8 & \multirow{3}{*}{3.8} & 8.7 & 3.9 \\
\hline & & & 27 de febrero & 06.00 & 4.2 & & 8.8 & 4.6 \\
\hline & & & 27 de febrero & 21.00 & 2.4 & & 13.3 & 10.9 \\
\hline
\end{tabular}

Fuente: elaboración propia

\section{Discusión}

Se ha abordado por primera vez un estudio de la isla de calor en la ciudad de Palma mediante el método de los transectos urbanos, tres en el caso del presente trabajo, y para cada uno de los cuales se han tomado muestras de temperatura en un total de catorce mediciones de campo, cinco de ellas en verano y nueve en invierno, en horario diurno y nocturno. El fenómeno de la isla de calor se manifiesta en trece de estas mediciones, con unos valores de intensidad que oscilan entre $1.4^{\circ} \mathrm{C}$ y $5.8^{\circ} \mathrm{C}$, dependiendo tanto del trazado de los transectos como de la fecha y el horario de la toma de muestras. En todos los transectos menos en el del mediodía de septiembre se ha detectado el fenómeno, aunque con intensidades variables, siendo el primero de ellos -el más largo y que atraviesa la ciudad de norte a sur- aquel en el que la isla de calor mejor se manifiesta. Su valor medio es de $4.9^{\circ} \mathrm{C}$, frente a los $3.1^{\circ}$ y $3.8^{\circ} \mathrm{C}$ de los dos otros recorridos.

El análisis estacional muestra cómo en verano, si se exceptúa el caso de la noche del 10 de julio, con una IICU máxima de sólo $2.2^{\circ} \mathrm{C}$, la intensidad máxima de la isla de calor es similar tanto de día como de noche (entre $4.1^{\circ}$ y $4.9^{\circ} \mathrm{C}$ ). En otoño e invierno, en función de los recorridos diseñados, las intensidades son variables, sin que los resultados permitan establecer claras diferencias entre la isla de calor diurna y la nocturna. Así, en el transecto más largo los valores de IICU más elevados $\left(5.8^{\circ}\right.$ C) se alcanzan por la noche, pero para otros recorridos la intensidad de la isla de calor nocturna puede resultar mucho menor. Aunque febrero es el mes más frío del año en Palma, esto no impide que se registren casos con una IICU nocturna muy débil (1.4 $\mathrm{C}$ ). Sin embargo, las noches de las mediciones de noviembre fueron en términos generales tan frías como las noches de las mediciones de febrero, lo que sugiere que hay una relación directa entre unas condiciones de frío ambiental durante la noche y una intensificación nocturna de la isla de calor, como caber 
esperar si se supone que en las noches frías la demanda de calefacción por unidad de habitación es más alta, y por tanto la emisión de calor antropogénico a la atmosfera también es mayor.

Pese a las diferencias, es un hecho probado que en Palma hay una transición según la cual la temperatura aumenta conforme el sensor se adentra en un ambiente urbano. Sin embargo, una vez dentro de la ciudad, la amplitud térmica puede ser pequeña $\left(1.1^{\circ} \mathrm{C}\right)$ o algo mayor $\left(3.1^{\circ} \mathrm{C}\right)$. Que a veces sea algo alta significa que a ciertas horas del día se dan diferencias apreciables de temperatura entre unas zonas y otras de Palma. Por el contrario, que a veces sea pequeña significa que la ciudad se comporta como un medio homotérmico. En este último caso hay que atender a lo expuesto por Guijarro (1998) cuando analiza la influencia de la urbanización en las series termométricas de las Baleares, en el sentido de que en la ciudad se observa una disminución de la oscilación termométrica diaria a causa de la mayor capacidad calorífica de los materiales de construcción, así como por la mayor superficie de intercambio existente en las áreas urbanizadas.

Sea como sea, la variación de la temperatura a lo largo de los recorridos, y en las dos épocas del año estudiadas, muestra un contraste térmico entre el interior de la ciudad y su afueras, lo que demuestra algo bien conocido, y es que el régimen térmico de un lugar es muy sensible tanto a los usos del suelo como a las características geométricas de las calles y edificios de la plaza estudiada, así como a los cambios geomórficos del terreno, aunque sean pequeños. De esta manera, en Palma la temperatura desciende en las vaguadas con cobertura arbórea más o menos densa, aumenta cuando la densidad edificatoria y de tráfico es mayor, y aumenta también en las áreas confinadas de calles cortas y estrechas, aun en el caso de que en éstas el tráfico sea escaso. Por otra parte, si bien durante los recorridos el aire se muestra progresivamente más cálido a medida que se desciende de altitud (en el caso del transecto número 1, su origen está a 85 m sobre el nivel del mar), el caso es que la variación y distribución espacial de las temperaturas no responde tanto a criterios de altitud como a los cambios ambientales inducidos por la geometría interna de la ciudad y la magnitud de las actividades humanas.

En Palma, el efecto de isla de calor es más acusado en el lado oriental de la Ciudad Antigua intramuros, localización plenamente coincidente con los resultados de un estudio similar (Ramis et al., 2002) según el cual las mayores temperaturas también se registran en el centro histórico de la ciudad. Esto indica una disminución radial de las temperaturas respecto al centro del abanico que forma el entramado urbano de Palma. En el interior del casco histórico, las intensidades máximas se constatan normalmente en la misma zona -la barriada de Es Sindicat-, constituida por una trama urbana de calles cortas y estrechas, y en donde por este motivo el escape natural de la radiación acumulada parece ser menor que en otros ejes de la ciudad, aunque en esos ejes el volumen de tráfico sea mayor. Además, Es Sindicat es la barriada más poblada de la Ciudad Antigua, lo que colabora para que resulte ser una de las zonas más cálidas de Palma durante la noche o a primera hora de la mañana. Con todo, no puede obviarse el carácter bifocal que a veces adopta el 
fenómeno, aunque en general puede hablarse de una única burbuja de calor urbano, relativamente bien organizada y localizada, independientemente de que dentro de ella aparezcan focos circunstanciales de frescor, sin capacidad para destruirla.

En buena parte de las fechas y horas de medición estos enfriamientos aparecen en los mismos lugares, básicamente junto al hospital periférico de Son Espases, en la vaguada de la Rambla y en el Passeig de Mallorca, coincidiendo con el emplazamiento de un cauce de agua por el que se canaliza eficazmente aire más frío procedente de las afueras de la ciudad. Si bien los focos de frescor están emparejados con pequeñas depresiones del terreno, en su aparición también juega un papel importante la presencia profusa de vegetación arbórea. La vegetación, según Givoni (1989), siempre juega a favor de la reducción de los efectos de la isla de calor, incluso cuando se trata de pequeñas plantas adosadas a los tejados y fachadas (Spiller, 1993). Los efectos de enfriamiento por la vegetación han sido medidos y reportados para el caso de numerosas ciudades, como Göteborg, Suecia (Upmanis, 1998) o ciudad de México (Jauregui et al., 1997).

En términos comparativos, la ciudad de Palma manifiesta un fenómeno de isla de calor que llega a alcanzar intensidades moderadas, semejantes a las que se han consignado en otras ciudades españolas de tamaño medio, como Las Palmas de Gran Canaria, con una IICU máxima invernal de $5.3^{\circ} \mathrm{C}$ (Ruiz-Flaño et al., 2008), o Zaragoza, en la que consignó una intensidad en torno a los 5.0 C (Cuadrat et al., 1993). Los resultados en Palma también tienen puntos en común con los concernientes a la ciudad de lbiza, estudiada por Serra (2007), en donde se consigna una intensidad máxima de $6.4^{\circ} \mathrm{C}$, valor que sorprende en una ciudad como ésta, de pequeño tamaño. En cualquier caso, ya que los cambios poblacionales y urbanísticos son hoy en día muy rápidos, se antoja arriesgado establecer comparaciones entre la actual isla de calor de Palma y la de poblaciones con estudios similares pero diez o casi veinticinco años más antiguos, o poblaciones para cuyo estudio de la isla de calor se han empleado métodos distintos al de los transectos, o simplemente ciudades no litorales.

\section{Conclusiones}

En el presente trabajo, mediante el método de los transectos urbanos, realizados en distintas fechas, se ha confirmado la presencia del fenómeno de isla de calor en la ciudad de Palma, además de ciertos contrastes de temperatura en su interior, que pueden tener gran interés a la hora de proyectar nuevos espacios urbanos o reordenar los existentes, siguiendo criterios ambientales. En Palma se forman burbujas urbanas más cálidas preferentemente en sectores de la antigua ciudad intramuros, pero también en zonas en las que por las características geométricas de los edificios, la densidad de población y la intensificación de la actividad urbana, es más fácil la acumulación de calor. De los tres transectos diseñados, es el primero el que muestra un fenómeno de isla de calor mejor definido, lo que induce a pensar que debe ser éste el transecto que atender en futuros 
trabajos, pues atraviesa de norte a sur el semicírculo exterior de la Vía de Cintura y el semicírculo interior de las Avingudes, adentrándose en el antiguo casco urbano y alcanzando el frente litoral.

El trabajo ahora presentado abre la posibilidad de nuevas líneas de investigación, entre las que cabría destacar la ampliación de la extensión temporal de los datos de temperatura, con el objetivo de disponer de datos mensuales que conduzcan a una caracterización temporal completa de la isla de calor urbana de Palma. En relación con ello cabría estudiar y clasificar los escenarios sinópticos en los que se forma la isla de calor, y analizar los vínculos del fenómeno con las condiciones meteorológicas reinantes, principalmente las que se refieren a la cobertura nubosa y la velocidad del viento. Puede ser particularmente interesante estudiar la formación de una isla de calor en condiciones de brisa marina, pues las brisas, con sus frentes térmicos e higrométricos, han de modificar necesariamente los patrones térmicos de la ciudad, tanto temporales como espaciales. También se antoja interesante relacionar la isla de calor con la geometría de las calles mediante la relación matemática entre la altura de los edificios y la anchura de la calle.

Finalmente, los resultados obtenidos en el presente trabajo mediante trabajo de campo pueden ser cotejados con los datos de temperatura que se obtengan instrumentalmente mediante técnicas de teledetección espacial, y en concreto a partir del análisis de imágenes satelitales infrarojas. Todo ello con vistas a modelizar el fenómeno, y con esto a la elaboración de estudios de evolución y tendencia. Asimismo, no sería menos interesante valorar la contribución activa del calor urbano a un presumible incremento local de la precipitación en el lugar, por el refuerzo de la convección. Comprobadas las bondades del método de los transectos urbanos para la identificación de la isla de calor de Palma, éste método no es incompatible con el de las medidas simultáneas de la temperatura en distintos puntos de la ciudad. Ambos métodos pueden ser aplicados para identificar y describir el fenómeno en ciudades o en localidades del ámbito geográfico balear, continentales o litorales, que comparten unas características climáticas mediterráneas comunes, y en las que todavía no ha sido explorado el fenómeno.

Declaración responsable: Las/os autoras/es declaran que no existe ningún conflicto de interés en relación a la publicación de este artículo. Las tareas realizadas por los autores del artículo han sido las mismas en relación con la toma directa de datos mediante trabajo de campo. En relación con la redacción del artículo, el peso ha recaído en el autor Gabriel Alomar Garau. 


\section{Bibliografía}

Alomar Garau, G. (2012). Geografia de la brisa marina a Mallorca. Anàlisi espacial de la seva influència en les precipitacions d'estiu i la seva participació com a factor de localització (Doctoral dissertation). Universitat de les lles Balears. Retrieved from https://www.educacion.gob.es/teseo/mostrarRef.do?ref=990840\#

Alomar Garau, G. (2013). Las brisas marinas y su significación geográfica: El caso de Mallorca. Sémata: Ciencias sociais e humanidades, 25, 7-28. Retrieved from http://www.usc.es/revistas/index.php/semata/article/view/1152

Busato, F., Lazzarin, R. M., \& Noro, M. (2014). Three years of study of Urban Heat Island in Padua: Experimental results. Sustainable Cities and Society, 10, 251-258. doi: http://dx.doi.org/10.1016/j.scs.2013.05.001

Cuadrat, J. M., De La Riva, J., López, F., \& Martí, A. (1993). El medio ambiente urbano en Zaragoza. Observaciones sobre la isla de calor. Anales de Geografía de la Universidad Complutense, 13, 127-138. doi: http://dx.doi.org/10.5209/AGUC.32824

Dahech, D., \& Beltrando, G. (2012). Observed temperature evolution in the City of Sfax (Middle Eastern Tunisia) for the period 1950-2007. Climatic Change, 114(3), 689-706. doi: http://dx.doi.org/10.1007/s10584-012-0420-x

Dorta, P., Marzol, M. V., \& Rodríguez, J. (1992). Estudio del clima urbano en una ciudad litoral. El caso de Santa Cruz de Tenerife (Islas Canarias). In VI Trobades Científiques a la Mediterrània. Energia, medi ambient i edificació (pp. 69-89). CIRIT, Generalitat de Catalunya, Barcelona.

Givoni, B. (1989). Urban design for different climates (Report WMO-TD, 346). World Meteorological Organization. Retrieved from https://library.wmo.int/pmb_ged/wmotd_346_en.pdf

Guijarro, J. A. (1998). Influencia de la urbanización en las series termométricas de Baleares. In $N$ Reunión de Climatología: El clima y el factor urbano (pp. 305-314). Madrid, February 27-28.

Hernández, A., Márquez, J. A., Rivero, A., \& Romero, L. (2001). La isla de calor en Las Palmas de Gran Canaria: magnitud, distribución espacial y morfología urbana. In A. Pérez-Cueva, E. López Baeza, \& J. Tamayo Carmona (Coords.), El tiempo del clima (pp. 519-530). Valencia: Editorial Garmas.

Jauregui, E. (1997). Heat island development in Mexico City. Atmospheric Environment, 31, 38213831. doi: http://dx.doi.org/10.1016/S1352-2310(97)00136-2 
Jiménez, M. A., Cuxart, J., Mira, A., \& Martínez, D. (2006). Local nocturnal circulations in the island of Majorca: mesoscale modelling and verification. Tethys, 3, 123-134. doi: http://dx.doi.org/10.3369/tethys.2006.3.09

López Gómez, A., \& Fernández García, F. (1984). La isla de calor en Madrid: avance de un estudio de clima urbano. Estudios Geográficos, 174, 5-34.

Martín-Vide, J., \& Moreno García, M.C. (1992). Avance de resultados sobre la isla de calor de Barcelona y de otras ciudades catalanas. In VI Trobades Científiques de la Mediterránea. Energia, Medi Ambient i Edificació (pp. 55-68). CIRIT, Generalitat de Catalunya, Barcelona.

Martin-Vide, J., Moreno, M. C., \& Esteban, P. (2003). Spatial Differences in the Urban Heat Island of the Preand the Post-Olympic Barcelona (Spain). Paper presented at the Fifth International Conference on Urban Climate. September, 1-5, Lodz, Poland.

Martínez, J. (2014). Estudio de la isla de calor de la ciudad de Alicante. Investigaciones Geográficas, 62, 83-99. doi: http://dx.doi.org/10.14198/INGEO2014.62.06

Marzol, M. V., Dorta, P., \& Rodríguez, J. (1991). Variations temporelles et particularités de la temperatura horaire dans la ville de Santa Cruz de Tenerife (lles Canaries). Publications de I'Association Internationale de Climatologie, 5, 43-53.

Montávez, J. P., Rodríguez, A., \& Jiménez, J. I. (2000). A study of the urban heat island of Granada. International Journal of Climatology, 20, 899-911. doi: http://dx.doi.org/10.1002/1097-0088(20000630)20:8<899::AID-JOC433>3.0.CO;2-I

Moreno García, M. C. (1990). Estudio del clima urbano de Barcelona: la isla de calor. Departamento de Geografía Física y AGR (Doctoral dissertation). Universitat de Barcelona, Spain.

Moreno García, M. C. (1994). Intensity and form of the urban heat island in Barcelona. International Journal of Climatology, 6, 705-710. doi: http://dx.doi.org/10.1002/joc.3370140609

Moreno García, M. C. (1997). Una propuesta de terminología castellana en Climatología Urbana". Investigaciones geográficas, 17, 89-98. doi: http://dx.doi.org/10.14198/INGE01997.17.08

Moreno García, M. C. (1998). Las investigaciones sobre el clima urbano en las ciudades españolas. In F. Fernández, E. Galán, E., \& R. Cañada, R. (Coords), Clima y ambiente urbano en ciudades ibéricas e iberoamericanas (pp. 177-196). Madrid: Editorial Parteluz.

Moreno García, M.C. (2007). Climatología urbana. In J. M. Cuadrat, \& J. Martín Vide (Eds.), La Climatología española. Pasado, presente y futuro (pp. 181-206). Zaragoza: Editorial Prensas Universitarias de Zaragoza. 
Moreno García, M. C., \& Serra Pardo, J. A. (2016). El estudio de la isla de calor urbana en el ámbito mediterráneo: una revisión bibliográfica. Biblio3W, XXI(1179). Retrieved from http://www.ub.edu/geocrit/b3w-1179.pdf

Oke, T. R. (1973). City size and the urban heat island. Atmospheric Environment, 7, 769-779. doi: http://dx.doi.org/10.1016/0004-6981(73)90140-6

Oke, T. R. (1987). Boundary Layer Climates. London: Routledge.

Precedo, A. (1996). Ciudad y desarrollo urbano. Madrid: Síntesis.

Quereda Sala, J., Montón Chiva, E., \& Escrig Barberá, J. (2003). Un análisis experimental del efecto urbano sobre las temperaturas. Investigaciones Geográficas, 43, 5-17. doi: http://dx.doi.org/10.14198//NGEO2007.43.01

Ramis, C., Perelló, J., \& Gual, M. (2002). La isla de calor urbana en Palma de Mallorca. Revista española fe Física, 16(1), 39-43. Retrieved from http://revistadefisica.es/index.php/ref/article/view/1224

Ruiz-Flaño, P., Romero Martín, L., Máyer Suárez, P., \& Hernández Cordero, A. (2008). La isla de calor en Las Palmas de Gran Canaria: Intensidad, distribución y factores condicionantes. Boletín de la Asociación de Geógrafos Españoles, 47, 157-173. Retrieved from http://www.agegeografia.es/ojs/index.php/bage/article/view/2034

Saaroni, H., Bendor, E., Bitan, A., \& Potchter, O. (2000). Spatial distribution and microscale characteristics of the urban heat island in Tel Aviv, Israel. Landscape and Urban Planning, 48(1-2), 1-18. doi: http://dx.doi.org/10.1016/S0169-2046(99)00075-4

Sarricolea, P., Aliste, E., Castro, P., \& Escobedo, C. (2008). Análisis de la máxima intensidad de la isla de calor urbana nocturna de la ciudad de Rancagua (Chile) y sus factores explicativos. Revista de Climatología, 8, 71-84.

Serra Pardo, J. (2007). Estudio de la isla de calor de la ciudad de Ibiza. Investigaciones Geográficas, 44, 55-73. doi: http://dx.doi.org/10.14198/INGEO2007.44.03

Serra Pardo, J. (2016). El fenómeno de la isla de calor en dos ciudades turísticas. Los casos de Ibiza y Lloret de Mar (Doctoral dissertation). Universitat de Barcelona.

Sobrino, J. A., \& Oltra-Carrió, R. (2012). La campaña DESIREX en Madrid. Determinación de la isla de calor. In F. Fernández, E. Galán, \& R. Cañada (Eds.), Clima, ciudad y ecosistemas. Ponencias y conferencias invitadas al VII Coloquio de la Asociación Española de Climatología (pp. 141164). Barcelona: Publicaciones de la Asociación Española de Climatología (AEC), Serie B, núm. 5. 
Soler Temprano, X. (1998). Avance sobre la isla de calor en Girona. In F. Fernández, E. Galán, \& R. Cañada (Coords.), Clima y ambiente urbano en ciudades ibéricas e iberoamericanas (pp. 281-291). Madrid: Editorial Parteluz.

Spiller, M. (1993). Roof gardens and green façades for the improvement of urban environments (B.L. Thesis). University of NSW.

Troya, J. A. (2007). L'illa de calor nocturna a Inca. In VIII Jornades d'Estudis Locals, Inca. Ajuntament (pp. d'Inca Retrieved from http://ibdigital.uib.cat/greenstone/collect/memoriesUIB/index/assoc/Troya_Lo.dir/Troya_L opez_Josep_Antoni.pdf

Troya, J. A., \& Capó, D. (2012). L'illa de calor nocturna a diversos nuclis de població a Mallorca. D. Royé et al. (Coord.), XIII Coloquio Ibérico de Geografía. Respuestas de la Geografía Ibérica a la crisis actual (pp. 1175-1187). Santiago de Compostela: Meubook.

Unger, J., Sümeghy, Z., \& Zoboki, J. (2001). Temperature cross-section features in an urban area. Atmospheric Research, 58, 117-127. doi: http://dx.doi.org/10.1016/S0169-8095(01)00087-4 Upmanis, H., Eliasson, I., \& Lindqvist S. (1998). The influence of green areas on nocturnal temperatures in a high latitude city (Göteborg, Sweden). International Journal of Climatology, 18, 681-700. doi: https://doi.org/10.1002/(SICI)1097-0088(199805)18:6<681::AIDOC289>3.0.CO;2-L 